\title{
Corpo, violência sexual, vulnerabilidade e educação libertadora no filme "Preciosa: uma história de esperança"
}

Marcos Roberto Godoi ${ }^{1}$

Luciene Neves $^{2}$

GODOI, M.R.; NEVES, L. Body, sexual violence, vulnerability and liberation education in the film "Precious: based on the novel "push' by sapphire"*. Interface - Comunic., Saude, Educ., v.16, n.41, p.409-21, abr./jun. 2012.

The aim of this study was to analyze the representations of body (race, obesity and beauty), sexual violence and aspects of vulnerability, education and emancipation faced by the protagonist of the film "Precious: based on the novel 'push' by sapphire". The analysis identified representations of the fat and black body, rejection and prejudice, the desire to be beautiful and famous, the body's value and its beauty. The protagonist's mother explores and violates her physically and psychologically. She also covers up the sexual abuse done by her husband and blame the daughter for it. In this direction we could say that the violence has a diffuse characteristic. Regarding the sexual violence, vulnerability was identified in the individual, social and institutional dimensions. The education played an important role in the protagonist process of emancipation from the situation of oppression and vulnerability.

Keywords: Body. Body image. Sexual violence. Vulnerability. Liberation education.
O objetivo deste estudo foi analisar as representações de corpo (raça, obesidade e beleza), de violência sexual e os aspectos de vulnerabilidade, educação e emancipação vividos pela protagonista na trama do filme "Preciosa: uma história de esperança". A análise permitiu identificar representações do corpo gordo e negro: de rejeição e preconceito; o desejo de ser bela e famosa; de valorização do próprio corpo e de sua beleza. A violência sexual tem caráter difuso, pois a mãe da protagonista a explora e a violenta física e psicologicamente, além de encobertar o abuso sexual cometido por seu marido e culpabilizar a filha pelo ocorrido. A vulnerabilidade foi verificada nas dimensões individual, social e institucional, no que se refere à violência sexual. Por outro lado, a educação desempenhou um papel importante no processo de emancipação da situação de opressão e de vulnerabilidade da personagem principal.

Palavras-chave: Corpo. Imagem corporal. Violência sexual. Vulnerabilidade. Educação libertadora.
· Título original do filme em inglês.

${ }^{1}$ Rede Municipal de Educação de Cuiabá. Rua Diogo Domingos Ferreira, n. 292. Bairro Bandeirantes, Cuiabá, MT, Brasil. 78010-210. mrgodoi78@hotmail.com

${ }^{2}$ Departamento de Educação Física Universidade do Estado de Mato Grosso. 


\section{Introdução}

Têm sido cada vez mais frequentes, na mídia, denúncias de violência sexual contra crianças e adolescentes. Devido à alta incidência e às consequências para o desenvolvimento afetivo, social e cognitivo da vítima e de sua família, o abuso sexual é considerado um grave problema de saúde pública (Habigzang et al., 2005).

De acordo com Berliner e Conte (apud Pfeiffer, Salvagni, 2005), a prevalência real do abuso sexual infantil é desconhecida, uma vez que muitas crianças não revelam o abuso, conseguindo falar sobre ele somente na vida adulta. As vitimizações sexuais são de difícil notificação devido a fatores como medo, falta de credibilidade no sistema legal e o silêncio cúmplice que as envolve (Ribeiro, Ferriani, Reis, 2004). De acordo com dados da Secretaria Especial de Direitos Humanos da Presidência da República (SEDH), a cada oito minutos, um menor de idade é vítima de abuso sexual no Brasil; em $80 \%$ dos sessenta mil casos registrados em 2005, as vítimas foram meninas com idades entre dois e dez anos, mas só $2 \%$ dos casos são denunciados e, na maioria das ocasiões, a impunidade se dá porque os culpados são os pais ou padrastos ${ }^{3}$.

Sendo assim, buscamos apresentar algumas reflexões sobre este fenômeno, a partir da discussão do filme "Preciosa: uma história de esperança" (Preciosa, 2009), do diretor Lee Daniels. O objetivo deste estudo foi analisar as representações de corpo (raça, obesidade e beleza), de violência sexual e os aspectos de vulnerabilidade, educação e emancipação vividos pela protagonista na trama do longa-metragem. No que tange à metodologia, selecionamos, como corpus de análise, algumas cenas e diálogos do filme. Estes foram agrupados em três categorias: a) corpo, raça, obesidade e beleza; b) vulnerabilidade e violência; c) educação libertadora e emancipação.

A análise foi desenvolvida com base na literatura relacionada ao tema e na perspectiva dos Estudos Culturais. Louro (2000) refere-se ao cinema como "um movimento permanente de representações", tornando-se uma pedagogia cultural. De acordo com Giroux (2001, p.90):

Ao analisar a toda a gama dos lugares diversificados e densamente estratificados de aprendizagem, tais como a mídia, a cultura popular, o cinema, a publicidade, as comunicações de massa e as organizações religiosas, entre outras, os Estudos Culturais ampliam nossa compreensão do pedagógico e de seu papel fora da escola como o local tradicional de aprendizagem.

Representação é um conceito-chave para articular a análise do filme, pois é entendido, na perspectiva dos Estudos Culturais, como um processo de produção de significados sociais através dos diferentes discursos. É por meio dos significados que o mundo social é representado e conhecido de certa forma, e não de outra. Os significados não são criados de forma individual e desinteressada, mas são produzidos e postos em circulação mediante relações sociais de poder (Silva, 2001).

Alguns educadores e estudiosos têm utilizado filmes para abordar temas, discutir valores, atitudes ou práticas sociais, tais como: Abreu (2005) lança reflexões sobre o abuso sexual infantil; Fischer (2008) discute as relações entre cultura do sucesso e sexualidade, com foco na infância, enfatizando as questões de gênero; Maestrelli e Ferrari (2006) relatam uma experiência com o filme "O óleo de Lorenzo" na disciplina de Genética Médica; Oliveira, Oliveira e Iguma (2007) ressaltam as possibilidades da utilização do filme "Copacabana" como recurso no
${ }^{3}$ Disponível em: <http:/ /noticias.uol.com.br/ ultnot/efe/2006/05/18/ ult1766u16271.jhtm>. Acesso em: $20 \mathrm{fev}$ 2011. 


\footnotetext{
${ }^{4}$ Sapphire é o nome artístico de Ramona Lofton, mulher, negra, poetisa performática e autora do livro Push. Foi professora no Bronx, bairro mais pobre de Nova lorque, seus alunos eram, na maioria, negros e latinos.
}

processo de ensino em Gerontologia; Meneghel (2008) relata uma experiência com o filme "O homem elefante", abordando aspectos relacionados aos processos de exclusão baseados na diferença e na doença como estigma. Ainda assim, não encontramos nenhum estudo que aborda o tema da violência sexual e as suas relações com a vulnerabilidade e com o processo educativo.

A seguir, vamos apresentar a análise dos dados, com base nas três categorias de análise.

\section{Corpo, raça, obesidade e beleza}

O filme "Preciosa: uma história de esperança" é baseado no romance Push de Sapphire ${ }^{4}$. Passa-se em 1987, no Harlem, bairro pobre de Nova lorque, e conta a história de Claireece Preciosa Jones. Ela é representada como adolescente, mulher, negra, obesa, pobre e analfabeta. Sofre preconceito e violência na escola, no bairro onde mora e na sua família. Em uma das primeiras cenas do filme, ela diz:

Preciosa: "Queria ter um namorado de pele clara e cabelo bom. E queria ser capa de revista. Mas antes queria aparecer num dos vídeos da Bet. Minha mãe disse que eu não sei dançar. Falou que ninguém quer ver meu traseiro rebolando".

A adolescência é uma fase na qual o interesse por relacionamentos afetivos começa a se manifestar. Preciosa gostaria de ter um namorado branco e com o cabelo "bom", ou seja, fica subentendido que ela percebe os negros e seus cabelos como ruins. Provavelmente, porque não é este tipo de beleza que é divulgado na mídia e valorizado pela sociedade. Seu corpo é a antítese do corpo apreciado nas sociedades ocidentais industrializadas.

A mídia exerce uma importante influência na construção do padrão estético corporal. De acordo com Goldenberg e Ramos (2002), a exigência da boa forma física acaba atingindo os "simples mortais", que são bombardeados cotidianamente por imagens de rostos e corpos perfeitos, seja através do cinema, da televisão, da publicidade e matérias de jornais e revistas. Goellner (2003a) destaca que existem várias pedagogias em circulação, não só na área escolar, mas, também, os filmes, músicas, revistas e livros, imagens, propagandas são locais pedagógicos que estão a dizer de nós, seja pelo que exibem ou pelo que ocultam. Dizem também de nossos corpos e, por vezes, de forma tão sutil que nem mesmo percebemos quanto somos capturadas/os e produzidas/os pelo que lá se diz.

Em vários momentos do filme, Preciosa se imagina como uma estrela de cinema, uma atriz famosa, uma cantora, uma modelo em ensaio fotográfico. Normalmente, essas situações ocorrem quando ela sofre alguma violência. Estes "sonhos" revelam o desejo de Preciosa de ser aceita, popular, querida, de ter a atenção que não recebe de quase ninguém. Em uma das cenas, depois de tomar banho, ela começa a se arrumar na frente de um espelho. Ao invés de se ver refletida, ela vê a imagem de uma jovem loira, dentro do padrão estético valorizado para o corpo feminino. No entanto, na maioria das vezes que ela se imagina diferente do que é - uma "celebridade" -, ela se vê com o corpo que tem, mas aparece "produzida": maquiada, bem vestida e feliz. Fica subentendido que ela gostaria de ser aceita com o corpo que possui, sem ter de se enquadrar no padrão estético hegemônico pautado pela magreza ou pelo corpo atlético.

Em outra cena, após fazer um teste para entrar na escola alternativa, em virtude de ter sido expulsa da escola convencional porque estava na sua segunda gravidez, ela desabafa: 
Preciosa: "Sempre tem algo errado com esses testes. Fica parecendo que eu não tenho cérebro. Fica parecendo que eu e minha mãe, a família toda, que a gente é idiota. Só uma gordura feia e preta para ser jogada fora. Vai arrumar o que fazer. Às vezes eu queria estar morta. [...]".

Nesta passagem, podemos perceber a representação de rejeição e preconceito em relação ao seu corpo e sua raça, uma vez que ela se define de forma negativa, assim como sua família. Pode-se dizer que um dos efeitos de tal representação é sentir-se inferiorizada psicologicamente, bem como a internalização do preconceito. Conforme Novaes e Vilhena (2003), a gordura, frequentemente associada com a feiúra, sofre uma das maiores formas de discriminação nas sociedades que cultuam o corpo. Soma-se a isto o fato de ser mulher, negra e pobre, recaindo sobre si várias formas de estigma e preconceito. De acordo com Carvalho e Martins:

No contexto atual, a obesidade recebe duas definições: uma como um estado desviante dos padrões de normalidade na cultura e, nesse sentido, o corpo gordo é definido como algo anormal, porque difere da idéia de indivíduo normal, construída em um contexto social, no qual se atribui normalidade a um modelo de corpo com uma silhueta magra e/ou musculosa; e outra, a obesidade pode ser compreendida como uma doença, se ela representa um fator gerador de impotência do corpo e reduz as possibilidades de vida de um indivíduo no ambiente que Ihe é próprio. (Carvalho, Martins, 2006, p.213)

No entanto, um corpo gordo pode estar numa realidade saudável e aumentando sua potência de agir. Se, por um lado, este tipo de corpo se desvia dos padrões vigentes de beleza, contudo, ele não se desvia de sua própria natureza humana, de se sentir e perceber o ambiente à sua volta, afetando-se com as impressões do mundo. Deste modo, uma classificação antropométrica não avalia a saúde dos corpos, seja por seu caráter estático, que perde a percepção do movimento, seja porque reduz o corpo ao visível e mensurável, ignorando o psíquico, o dinâmico, o vivencial, ou seja, a condição efetiva daquele corpo junto à vida e às suas atividades e projetos (Carvalho, Martins, 2006).

Em outro momento da película, Mary, a mãe de Preciosa, a obriga a comer, mesmo sem estar com fome. Numa conversa com a assistente social, ela diz:

Preciosa: "Minha mãe é uma baleia no sofá. Diz que eu como toda hora, mas vive me obrigando a comer. Aí ela me chama de balofa. Diz que o apartamento é pequeno por minha causa. A única vez que ela sai é para jogar nos números (loteria). Acha que eu vou ficar com ela o dia todo, com as cortinas abaixadas, vendo TV, comendo, vendo TV, comendo de novo. Pode me ajudar com isso? Tá a fim de falar de outra coisa?" (Silêncio).

Nesta passagem, percebemos a influência da sua mãe em relação ao seu comportamento alimentar e sedentário. Mary apresenta os mesmos hábitos de alimentação e de inatividade física, mas Preciosa é mais gorda do que a mãe, que se aproveita disto para agredir e culpabilizar a filha. Conforme Goldenberg e Ramos (2002), a gordura e a flacidez ou a moleza são tomadas como símbolos da indisciplina, do desleixo, da preguiça, da falta de virtude, ou seja, da falta de investimento do indivíduo em si.

No entanto, Palma e Vilaça (2010) apresentam dados que desconstroem a ideia de responsabilidade individual, e robustecem a noção de transmissibilidade dos fenômenos associados à saúde. Em síntese, as pesquisas por eles revisadas evidenciam a disseminação da obesidade numa rede social, de tal forma que o estado corporal dos amigos e parentes contribui para a condição do estado obesogênico do sujeito. Além disto, mostram que níveis de atividade física dependem de fatores psicossociais e demográficos, tais como: nível de escolaridade, raça, renda, estado conjugal, tipo de ocupação, pertencimento a grupos de praticantes de exercícios físicos, isolamento social, satisfação com a vida etc.

Noutra cena, Preciosa está na sala de espera para falar com a assistente social, e pensa (com voz em off): 
Preciosa: "Semana passada a Sra. Rain (professora da escola alternativa) mandou a gente escrever o que a gente queria ser. Escrevi que queria ser bem magra, com a pele clara e cabelo comprido. Ela leu e disse que eu era bonita do jeito que eu sou. Mas de algum jeito, agora, eu não sei por que, mas acho que ela tá certa".

A assistente social chama Preciosa; antes de subir a escada, ela olha seu corpo num espelho e pensa: "Acho que ela tá certa". Esta cena evidencia a mudança de valor em relação à representação do seu corpo. Antes, ela não tinha nenhuma referência sobre sua beleza. A professora da escola alternativa tratou de desenvolver a estima de Preciosa, reforçando que se pode ser bela do jeito que se é, que há diferentes formas de beleza. Goellner (2003b) afirma que as mulheres não são meros objetos nos quais se direcionam os padrões estéticos e comportamentais. Elas interagem no seu tempo com estes padrões, e aprendem diferentes maneiras de serem belas e femininas. Elas tanto podem se reconhecer e se assumir nestes padrões ou não.

\section{Vulnerabilidade e violência}

No campo da saúde, o quadro conceitual da vulnerabilidade está relacionado ao esforço de superação das práticas preventivas apoiadas no conceito de risco. Ele surge no contexto de enfrentamento da epidemia da aids, após o uso dos conceitos de grupo de risco e de comportamento de risco. No entanto, a discussão sobre a vulnerabilidade tem-se expandido para outras áreas da saúde (Ayres et al., 2006). No âmbito deste artigo, utilizaremos a conceituação de vulnerabilidade aplicada à suscetibilidade dos personagens do filme à violência sexual, sendo analisada em três dimensões: a individual, a social e a programática ou institucional.

Conforme Ayres et al. (2006), a dimensão individual da vulnerabilidade refere-se ao grau e à qualidade das informações de que o sujeito dispõe sobre a aids (e sobre a violência sexual) e suas formas de transmissão, bem como sua capacidade de elaborá-las e incorporá-las em seus comportamentos e práticas de prevenção; a dimensão social é relacionada aos fatores contextuais que podem influenciar a vulnerabilidade individual, tais como: acesso aos meios de comunicação, escolarização, disponibilidade de recursos materiais, poder de influenciar decisões políticas, possibilidade de enfrentar barreiras culturais, estar livre de coerções violentas ou poder defender-se delas; e a dimensão programática ou institucional, relacionada à capacidade de resposta das instituições públicas (de saúde, educação, bemestar social e cultura) no que tange ao diagnóstico da situação e no encontro de caminhos para a superação (da violência sexual) e da contaminação pela aids (grifos e parênteses nossos).

No filme em questão, a vulnerabilidade pode ser identificada em vários momentos. Na parte inicial, Preciosa está na escola assistindo aula de matemática quando é chamada para ir até a diretoria. Lá, a diretora pergunta se ela está grávida. Não obtém resposta. Em seguida, a diretora diz:

Diretora: "Você tem 16 anos, ainda está no colegial e está grávida do segundo filho. Isso é correto Claireece?" Silêncio. "Está grávida de novo? O que que houve Claireece?"

Preciosa: "Eu fiz sexo Sra. Lichenstein."

Diretora: "Você já pensou um pouco na sua situação?"

Preciosa: Silêncio. "Eu estou ferrada. Valeu, eu vou voltar para matemática".

Diretora: "Senta. Sente-se imediatamente. Devíamos fazer uma reunião entre mim, você e sua mãe".

Preciosa: "Minha mãe tá ocupada".

Diretora: "Tudo bem e se eu fosse até a sua casa?"

Preciosa: "Se eu fosse você eu não faria isso".

Diretora: "Eu vou ter que suspender você".

Preciosa: "Não é justo, eu não fiz nada. Eu faço meu dever, minha nota é boa".

Diretora: "Acontece alguma coisa na sua casa? Se acontece alguma coisa eu quero que me diga agora".

Preciosa: Silêncio. 
A diretora da escola queria saber o que estava se passando com Preciosa e se dispôs a dialogar com a sua mãe. Mas, devido à situação de violência a que era submetida por sua família, Preciosa não queria que ela fosse até a sua casa. Preciosa acaba sendo transferida de escola devido a sua segunda gravidez. Pressupomos que o receio seja o de que meninas grávidas sejam "mau exemplo" para seus colegas.

Essa situação evidencia o estado de vulnerabilidade institucional, pois a escola não soube lidar adequadamente com a questão da gravidez e, muito menos, identificar a situação de abuso sexual. Além disto, a escola não oferecia um programa de educação sexual ou educação em saúde para abordar temas como gravidez na adolescência ou violência sexual.

Já em outro momento, Preciosa está lavando louça em casa. Sua mãe, sentada no sofá, pergunta se ela trouxe seu cigarro. Ela responde que não; Mary joga um objeto na cabeça da garota, que cai no chão e desmaia. Em pensamento, aparece a imagem de seu pai estuprando-a. A porta do quarto está aberta. A mãe passa e vê a cena e não faz nada. O pai dela diz: "O papai te ama, sabia?". Depois, Preciosa começa a se imaginar como uma celebridade, uma estrela de cinema assediada por jornalistas e fotógrafos. A mãe joga água no rosto da menina, acordando-a.

Nesta passagem, observamos a situação de violência física da mãe contra Preciosa, e é possível visualizar a violência sexual efetuada por seu pai. É a única passagem do filme em que ele aparece sendo representado como um pai ausente. Conforme Habigzang et al. (2005), a maioria dos casos de abusos sexuais cometidos contra crianças e adolescentes ocorre dentro de casa, praticados por pessoas próximas, que desempenham papel de cuidador destas (seja com laços sanguíneos, ou não, no caso de padrastos ou namorados das mães). Nestas situações, os abusos são denominados intrafamiliares ou incestuosos.

Segundo Furniss, citado por Habigzang et al. (2005), a dinâmica do abuso sexual intrafamiliar é desencadeada e mantida por uma trama complexa que envolve a "síndrome do segredo", ou seja, pelo fato de o abuso gerar repúdio social, o abusador tende a se proteger numa teia de segredo, mantida por meio de ameaças e barganhas à criança abusada; e também a "síndrome da adição", na qual o comportamento compulsivo de descontrole do agressor, que usa a criança para obter excitação sexual e alívio da tensão, gera dependência psicológica e sua negação. Além disso, outras formas de violência intrafamiliar podem estar associadas, como: negligência, abusos emocionais e físicos.

Felizardo et al. (apud Pfeiffer, Salvagni, 2005) destacam que, quando a filha é adolescente, a mãe, em muitos casos, consciente ou inconscientemente, começa a delegar à filha, em todos os seus aspectos, o seu pesado papel de mãe e esposa. Este aspecto pode ser visualizado em vários momentos do filme, nos quais a mãe obriga Preciosa a realizar as tarefas domésticas. Desse modo, podemos perceber a vulnerabilidade social, uma vez que Preciosa não conseguia defender-se da violência sexual praticada pelo seu pai e da exploração, violência física e psicológica efetuada por sua mãe.

Segundo Pfeiffer e Salvagni (2005), a violência sexual pode apresentar-se sob várias formas e níveis de gravidade, nem sempre acompanhada de violência física aparente. Isto dificulta muito a possibilidade de denúncia pela vítima e a confirmação diagnóstica pelos meios hoje oferecidos pelas medidas legais de averiguação do crime (Pfeiffer, Salvagni, 2005). Neste sentido, podemos identificar aspectos da vulnerabilidade institucional no que se refere ao enfrentamento da violência sexual.

Dando continuidade à descrição do filme, a diretora vai até a casa de Preciosa, mas não é recebida pela mãe. Pelo interfone, a diretora passa o endereço de uma escola alternativa para Preciosa estudar. Após, Mary diz que escola não ajuda ninguém, que era para ela se contentar com o dinheiro que recebe da assistência social. A sua mãe diz ainda:

Mãe: "Você é uma imbecil que não sabe merda nenhuma. Ninguém quer você, ninguém precisa de você. Sai por aí trepando com todo mundo, trepou até com meu homem, teve dois filhos com ele e um deles é um animal...".

Depois da discussão, a mãe atira objetos e corre atrás da filha para surrá-la. Nesta situação, há uma demonstração da violência psicológica que a mãe exercia sobre ela. Por ser de família pobre e Preciosa ter uma filha com síndrome de down - chamada de "Mongo", apelido proveniente de mongolóide -, elas recebiam ajuda do governo. Mary não queria perder este dinheiro, e explorava esta situação para viver com a renda da assistência social. No entanto, "Mongo" era criada por sua avó. Somente nos dias 
em que a assistente social ia fazer as visitas de acompanhamento familiar é que a avó levava "Mongo" para a casa de Preciosa.

Para receber a ajuda da assistência social, Preciosa tinha de frequentar a escola. No entanto, sua mãe não valorizava o saber e o conhecimento escolar, exercendo uma forma de controle e dominação. Porém, o mais impactante desta passagem é o tratamento e a forma depreciativa com que a mãe se referia a Preciosa, dizendo que ela não sabia de nada, que ninguém precisava dela, ninguém queria ela e que deveria tê-la abortado. Com certeza, valores negativos que abalavam a estima de sua filha.

Mais uma cena onde é retratada uma situação de vulnerabilidade social ocorre quando, depois de ir à escola alternativa, Preciosa está voltando para casa, andando pelas ruas do bairro, e um grupo de meninos agride-a verbalmente de "orca", de "feia", e um deles a empurra ao chão. Ela passa, então, a se imaginar fazendo um show. Na escola, ela também era vítima de agressões e xingamentos, mas não conseguia defender-se com argumentos, somente reagindo violentamente.

Numa das conversas que ela teve com a assistente social, Preciosa diz: “... também fui no médico. A dona Rain (professora) ficou besta quando soube que eu não tinha ido no médico (risos). Nem sei como eu tive o meu primeiro filho no chão da cozinha, com a minha mãe chutando a minha cabeça". Esta cena permite identificar aspectos da situação de vulnerabilidade institucional que estava enfrentando, pois Preciosa não tinha acesso ao serviço de saúde.

Depois que teve seu segundo filho no hospital, ela volta para casa com o bebê. Chegando lá, a mãe pede para segurar o menino. Depois, ela joga a criança no sofá e atira um objeto na filha. Mary acusa Preciosa de estragar sua vida, de ter roubado seu marido e pelo fato de perder o auxílio família. Elas brigam e Preciosa cai. A garota levanta e joga a mãe contra a parede, que atira um vaso de plantas contra a filha. Preciosa pega o bebê e vai embora, cai da escada, mas consegue segurar a criança. Mary pega a TV e joga escada abaixo, mas não acerta neles.

Depois de um tempo, a mãe de Preciosa vai procurá-la na escola. Diz a ela que seu pai morreu e que ele tinha o vírus da aids. Preciosa se imagina num ensaio fotográfico. No diálogo a seguir, fica evidente a situação de vulnerabilidade individual da mãe de Preciosa, pois ela desconhecia as formas de transmissão do vírus da aids.

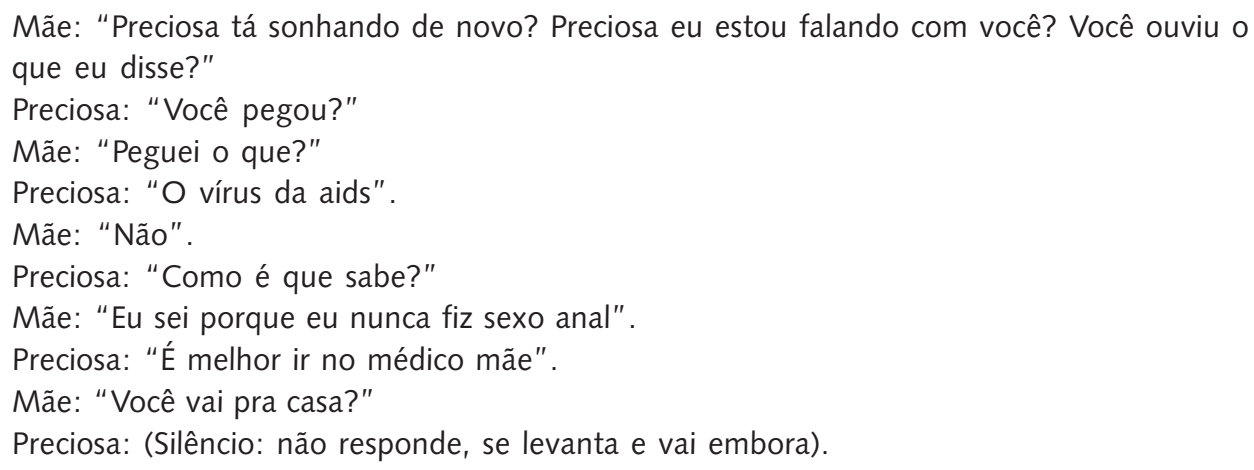

Após várias reuniões na assistência social, a situação de vulnerabilidade institucional começa a diminuir, quando a assistente descobre a relação incestuosa que ocorria na casa da família. Numa sessão de reconciliação, a assistente pergunta, para a mãe, sobre o abuso sexual contra sua filha. Depois de se esquivar das perguntas e até ser agressiva com a assistente, Mary conta que a primeira vez foi quando Preciosa tinha três anos, dizendo que a menina dormia na cama junto com eles. Falou que passou a odiar a sua filha, pois seu homem a desejava, e culpou, ainda, a garota por seu marido ter ido embora de casa. Segundo ela, a filha permitia o abuso, pois não falava nada, não gritava. Depois, Mary entrega "Mongo" para Preciosa, pede desculpas e diz que não quer receber mais os cheques (da Previdência). Preciosa conta sobre seus progressos na escola e suas perspectivas, e fala para a mãe que não quer vê-la nunca mais, pega os filhos e vai embora.

Conforme Hirsh (apud Pfeiffer, Savagnani, 2005), quando o incesto é revelado, em algumas situações, a mãe reage com ciúmes, como rival, e passa a colocar, na filha, a responsabilidade pelo 
ocorrido. A mãe teria dificuldade de reconhecer o incesto, pois seria o reconhecimento de seu fracasso como mãe e esposa. Por outro lado, a mãe pode sentir-se desprotegida pelo outro responsável, insegura por imaginar que realmente não seria ouvida, envergonhada tanto pelo que passa como pela sua impossibilidade de denunciar, por seu amor próprio reduzido; e, ainda, ameaçada por aquele de quem habitualmente depende física e emocionalmente, muitas vezes, ela se cala por toda sua vida (Pfeiffer, Savagnani, 2005).

\section{Educação libertadora, emancipação e esperança}

Antes, na escola convencional, Preciosa sentava no fundo da sala de aula, só ouvia o professor, nunca tinha ido ao quadro resolver alguma atividade. Tinha dificuldade de leitura, mas gostava das aulas de matemática e se saía bem nesta disciplina. Podemos identificar, aqui, uma situação de ensino parecida com a da educação bancária, nos termos de Paulo Freire (1987), ou seja, aquela prática educativa que subordina o educando, sufocando o gosto pela rebeldia, reprimindo a curiosidade, desestimulando a capacidade de desafiar-se, de arriscar-se, tornando-o um sujeito passivo.

A situação de vulnerabilidade a que Preciosa estava submetida começa a se alterar depois que ela passa a estudar na escola alternativa. Lá, a turma, em sua maioria, era composta de alunas negras ou latinas, que tinham dificuldades de aprendizagem. A professora Rain era polivalente, seu método de ensino era dialógico e problematizador, uma vez que trabalhava a leitura e a escrita através de diários, nos quais as alunas escreviam sobre sua vida, seus sonhos e projetos, suas dificuldades etc. Além disto, ela levava suas alunas para visitar museus e desenvolvia atividades mais participativas no contexto da sala de aula. Numa das cenas do filme, as alunas estão lendo suas redações. Preciosa pensa:

Preciosa: "Eu estou feliz porque eu estou escrevendo e também por causa que eu estou na escola. A Sra. Rain diz que vamos escrever todo dia no caderno. Ela vai escrever pra gente todo dia também. [...]. A mãe diz que a escola é uma merda, que ninguém aprende escrevendo em caderno. Ela tá errada nisso. Por causa que eu to aprendendo. [...]. Eu também penso na Mongo, sinto falta dela. Meu bebê tá pra chegar. Também vou ler pro meu bebê e enfeitar a parede dele. Escuta bebê, a mamãe não é burra. A mamãe ama você. Escuta".

Ela lê a sua fábula, agora com mais desenvoltura, mas começa sentir as contrações do parto e é levada para o hospital. Nesta passagem, podemos perceber a felicidade de Preciosa por estar progredindo na escola. Fica evidente a discordância dela em relação ao ponto de vista de sua mãe, que não acreditava na escola e que a considerava incapaz de aprender.

Na concepção freireana, a emancipação humana é uma conquista política, e se dá através de uma luta ininterrupta para a libertação das pessoas, de sua vida desumanizada pela opressão social. Através de um método de ensino dialógico, de problematização e reflexão crítica, é possível contribuir para esta emancipação. Segundo Freire (2000), a luta pela transformação social pode acontecer em diferentes lugares e momentos: em casa, nas relações familiares, na escola, no trabalho etc. Este processo emancipatório fica mais evidente à medida que o filme se desenrola, nas diferentes situações pedagógicas mediadas pela professora com suas alunas.

Outro aspecto que merece destaque são as relações de amizade. Preciosa não tinha muitos amigos quando estudava na escola convencional, mas, na escola alternativa, ela estabeleceu laços de amizade. O acolhimento dos amigos pode ser visualizado, por exemplo, quando suas colegas e professora vão até o hospital visitá-la; na cena em que o auxiliar de enfermagem lhe dá um cartão de Natal; ou, ainda, quando a professora organiza uma festa na escola para comemorar um prêmio da prefeitura pela evolução do aprendizado de Preciosa.

Numa cena que ocorre na escola, as alunas estão lendo seus diários, e chega o momento de Preciosa: 
Preciosa: "Eu não quero ler tudo que está aqui, só quero dizer do que se trata. Tá bom, os conselheiros da instituição (assistência social) perguntaram sempre da minha mãe e do meu pai, mas não querem saber deles. Eles só querem que eu trabalhe lá, só estão querendo uma empregada. É que eu roubei o meu arquivo e li. Só querem que eu trabalhe. Eu quero trabalhar, mas não pelos cheques da assistência".

Colega de sala: "E do que vai adiantar alguém como a Preciosa largar a escola antes de conseguir o diploma e ir trabalhar em alguma casa de gente branca? Ela nunca vai conseguir ser nada se ficar numa merda dessa".

Outra colega: "A Rondha (colega de sala) era empregada".

As alunas começam a discutir a situação das empregadas domésticas, salário, turno de trabalho, ter de abandonar a escola etc. Nesta sequência, podemos perceber a concepção crítica do ato de ler, a leitura de mundo, a compreensão do texto e do contexto, tal qual a concepção freireana de alfabetização de adultos, que entende esta como um ato político e um ato de conhecimento. "A leitura do mundo precede a leitura da palavra, daí que a posterior leitura desta não possa prescindir da continuidade da leitura daquele. Linguagem e realidade se prendem dinamicamente" (Freire, 2001, p.11), ou seja, não há dicotomia entre a leitura de mundo e a leitura da palavra, pois a leitura sempre se faz através das relações entre o texto e o contexto.

Por meio dos diários utilizados no processo de alfabetização das alunas, a professora estabelece um intenso diálogo com Preciosa sobre a sua situação.

Professora: "Onde estava sua avó quando seu pai abusou de você? Onde está a pequena Mongo agora? O que vai ser a melhor coisa pra você nessa situação?"

Preciosa: "Faz muita pergunta Srta. Rain. Queria poder parar de respirar. Só quero ser boa mãe".

Professora: "Ser boa mãe pode significar deixar o Abdul ser criado por alguém mais capacitado para atender as necessidades dele".

Preciosa: "Dona Rain, eu sou a melhor para atender meu filho" (começa a amamentar o filho, o olhar é de ternura).

Professora: "Quem vai te ajudar? Como vai se sustentar? Como vai continuar aprendendo a ler e escrever?"

Preciosa: "A assistência social ajudou minha mãe".

Professora: "Você viu como a assistência social ajudou sua mãe. Se conseguir o diploma, você pode ir à faculdade. Você pode ter tudo Preciosa".

Em uma atitude dialógica, a professora questiona sobre quem seria mais capacitado para criar Abdul (filho de Preciosa), sobre a dependência da assistência social, sobre o sustento dela e o futuro de seus estudos. O diálogo assume um papel central para uma educação libertadora na obra de Paulo Freire. Ele é a força que impulsiona o pensar crítico-problematizador em relação à condição humana no mundo. Além disto, ele abre caminhos para repensar a vida em sociedade, discutir nossas práticas culturais, nossa educação, a linguagem que praticamos e a possibilidade de agirmos de outro modo, transformando o mundo que nos cerca. O educador não pode se omitir de comunicar sua leitura de mundo, desde que fique claro que não existe apenas uma única leitura possível. Assim, "os homens se educam em comunhão, mediatizados pelo mundo" (Freire, 1987, p.39).

Depois que Preciosa ganha o bebê, ela volta para sua casa. Sua mãe a agride fisicamente e ela sai para procurar ajuda na escola alternativa. Como estava fechada, ela arromba a porta e fica esperando a professora e a secretária chegarem. A professora acaba levando Preciosa e o bebê para sua casa até que arrumem outro lugar. Ela descobre que sua professora é lésbica e mora com a companheira, Katherine. Preciosa ganha um presente de Natal delas e pensa:

Preciosa: "Por que as pessoas que nem me conhecem são mais legais comigo do que minha mãe e meu pai? Me sinto protegida. Minha vó tem medo da minha mãe. Por isso não me 
deixa morar com ela. A dona Rain diz para não ter medo de nada. Aposto que ela não tem medo da minha mãe. [...]. Minha mãe diz que gay é gente ruim. Mas mãe, não foram os gays que me violentaram! Gays não me deixaram sentada numa sala pra não aprender nada. E não tem gay vendendo crack para o pessoal do Harlem. [...]".

Podemos perceber aqui um processo de autorreflexão sobre as relações sociais. Preciosa desconstrói o preconceito em relação aos gays, introjetado pela sua mãe, e reconhece todo o apoio que a professora Rain estava dando a ela. De acordo com Freire (1978), a consciência crítica caracteriza-se pelo pensar autônomo e comprometido, levando ao engajamento sociopolítico. Substitui as explicações mágicas para explicar a realidade, e adota princípios e relações causais. Opera com pré-disposição para rever sua posição e se dá conta dos pré-conceitos que deformam as interpretações. Caracteriza-se, também, pela responsabilização dos seus atos, a atitude argumentativa dialógica e a receptividade diante do novo.

Na sala de aula, as alunas estão escrevendo em seus diários. Preciosa escreve: "Por que eu?". A professora vê e a chama. Ela diz: "Eu sou HIV positivo". Todas ficam em silêncio. A colega de turma pergunta: "E seu bebezinho está bem?". Preciosa diz: "Tá, tive que parar de dar de mamá".

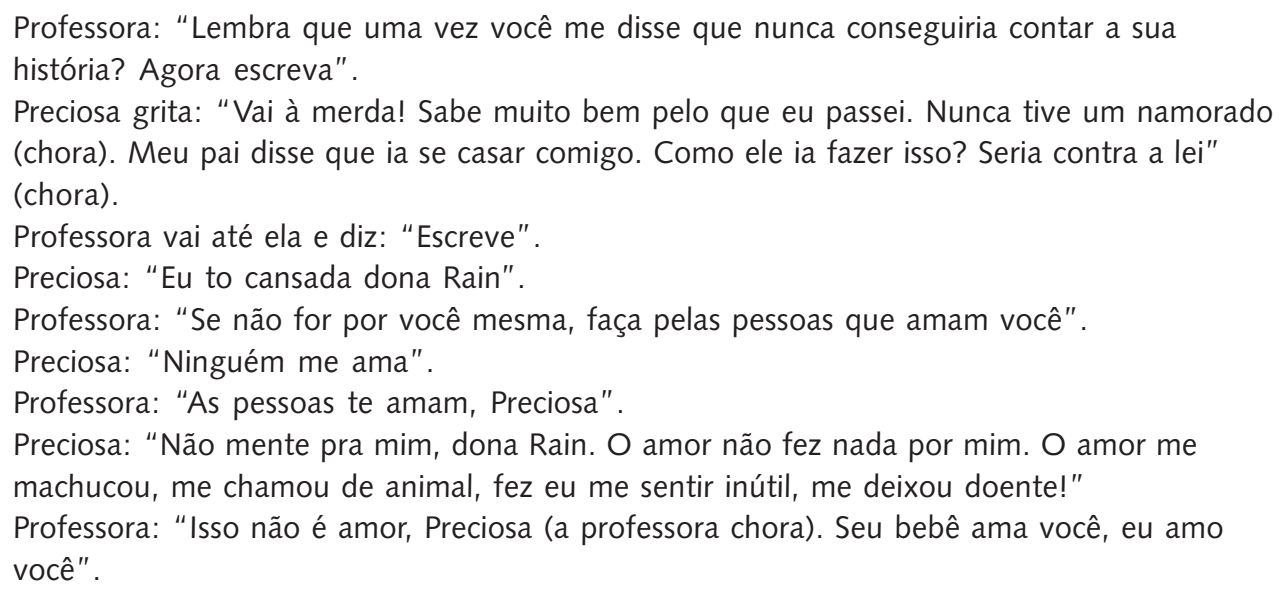

Temos aqui uma "situação-limite", vivenciada pela garota, que se altera quando a professora pede a ela para escrever. De acordo com Freire (1987), as situações-limite são constituídas por contradições que envolvem os indivíduos, produzindo uma aderência aos fatos, que são percebidos como fatalismo. Isto faz com que as pessoas se sintam impotentes, não enxergando as possibilidades de romper com tudo aquilo que as torna submissas, nem tampouco como poderiam responder de outro modo às tarefas que as situações-limite exigem. Assim, não enfrentam, nem buscam respostas aos desafios que elas carregam e que poderiam levá-las a mudar seu modo de viver.

A professora insiste para Preciosa escrever, numa tentativa de romper com a situação-limite. Mas a aluna se queixa que o amor não fez nada por ela, que o amor a machucou e a fez ficar doente. Rain então responde que isso não é amor, diz que seu filho a ama e ela também. Conforme Freire (1987, p.79), "a conquista implícita no diálogo é a do mundo pelos sujeitos dialógicos, não a de um pelo outro. Conquista do mundo pela libertação dos homens, não há diálogo, porém, se não há um profundo amor ao mundo e aos homens". A amorosidade percorre a obra de Paulo Freire e se materializa no afeto e compromisso com o outro, através da solidariedade e da humildade.

Em nossa análise, a educação desempenhou um papel importante para a emancipação das situações de vulnerabilidade e de opressão que Preciosa enfrentava. Ela possibilitou que a jovem pudesse ver os fatos de uma forma diferente, instrumentalizando-a para enfrentar as dificuldades da vida e dando-lhe esperança para viver dias melhores. Mesmo advinda de um contexto familiar e social violento, ela pretendia dar a seus filhos um futuro melhor. 


\section{Considerações finais}

Este trabalho não pretende esgotar todas as possibilidades de análise do filme, apresenta-se como uma leitura, dentre outras possíveis. Em nossa análise, pudemos identificar as representações em torno do corpo gordo e negro: de preconceito e rejeição; o desejo de ser bela e famosa; e após, de valorização do próprio corpo e de sua beleza.

Em relação às representações de violência, a mãe de Preciosa a explorava e a violentava, física e psicologicamente. Além disto, acobertava o abuso sexual cometido por seu marido e culpava a sua filha por ele a desejar. A vulnerabilidade individual foi identificada quando Preciosa não conseguia se defender da violência sexual; e o analfabetismo, que contribuía para que não encontrasse saídas para as situações-limite vivenciadas. E ainda, quando sua mãe tinha informações incorretas sobre as formas de transmissão do vírus HIV. A vulnerabilidade social foi constatada nas situações de exploração e violência na sua própria família, o preconceito e discriminação vivenciados na escola e em seu bairro, além das privações econômicas pelas quais passava. Já a vulnerabilidade institucional foi mostrada no contexto da escola, que a expulsou por estar na segunda gravidez, não identificando que ela estava sendo abusada sexualmente e nem oferecendo um programa de educação sexual. E, ainda, pela assistência social que demorou a identificar a violência sexual que ocorria em seu lar.

A professora da escola alternativa desempenhou um importante papel na vida de Preciosa. Seu método de ensino era problematizador, reflexivo e dialógico, contribuindo para uma educação como prática da liberdade, e para a emancipação da situação de opressão e de vulnerabilidade de sua aluna.

Conforme Ayres et al. (2006), as ações de redução da vulnerabilidade não podem ser efetivas e operacionais se ficarem restritas à esfera da saúde. A ação intersetorial é fundamental, e deve envolver, no mínimo, saúde e educação. No entanto, à medida que envolvemos as áreas do trabalho, bem-estar social, jurídica e cultural, as chances de melhores resultados aumentam proporcionalmente.

O problema da violência sexual é complexo e envolve vários fatores, daí a necessidade de um trabalho intersetorial para diminuir as vulnerabilidades. No entanto, nós, educadores e profissionais da saúde, podemos discutir este assunto em nossa prática profissional. Uma estratégia possível seria utilizar o filme "Preciosa" para problematizar e refletir sobre corpo, vulnerabilidade, violência sexual e educação libertadora.

O/a educador/a (professor/a ou profissional de saúde) desempenha um papel importante no processo de mediação pedagógica, devendo explorar as representações e os aspectos conceituais contidos na trama do filme. Além disto, seria interessante discutir, com os/as alunos/as, os mitos e verdades sobre a violência sexual; ler e discutir matérias jornalísticas sobre este assunto; realizar dramatizações e dinâmicas de grupo relacionadas ao tema, dentre outras estratégias pedagógicas que visem fortalecer as atitudes em defesa da vida.

\section{Colaboradores}

Marcos Roberto Godoi responsabilizou-se pela redação, edição e finalização do artigo. Luciene Neves Santos participou da edição e finalização do manuscrito. 


\section{Referências}

ABREU, M.A.M. Trágica trama: o abuso sexual infantil representado no filme Má Educação. 2005. Dissertação (Mestrado) - Universidade Católica de Brasília, Brasília. 2005.

AYRES, J.R.C.M. et al. Risco, vulnerabilidade e práticas de prevenção e promoção da saúde. In: CAMPOS, G.W.S. et al. (Orgs.). Tratado de saúde coletiva. 2.ed. São Paulo: Hucitec, 2006. p.375-418.

CARVALHO, M.C.; MARTINS, A. A obesidade como objeto complexo: uma abordagem filosófico-conceitual. In: BAGRICHEVSKY, M.; PALMA, A.; ESTEVÃO, A. (Orgs.). A saúde em debate na Educação Física. Blumenau: Nova Letra, 2006. v.2, p.203-22.

FISCHER, R.M.B. Pequena Miss Sunshine: para além de uma subjetividade exterior. Pro-Posições, v.19, n.2, p.47-57, 2008.

FREIRE, P. A importância do ato de ler: em três artigos que se completam. 42.ed. São Paulo: Cortez, 2001.

Pedagogia da indignação: cartas pedagógicas e outros escritos. São Paulo: EdUnesp, 2000.

Pedagogia do oprimido. 17.ed. Rio de Janeiro: Paz e Terra, 1987.

Educação como prática da liberdade. São Paulo: Paz e Terra, 1978.

GIROUX, H. Praticando estudos culturais nas Faculdades de Educação. In: SILVA, T.T. (Org.). Alienígenas na sala de aula: uma introdução aos estudos culturais em educação. Petrópolis: Vozes, 2001. p.85-103.

GOELLNER, S.V. A produção cultural do corpo. In: LOURO, G.L.; NECKEL, J.F.; GOELLNER, S.V. (Orgs.). Corpo, gênero e sexualidade: um debate contemporâneo na educação. Petrópolis: Vozes, 2003a. p.28-40.

. Bela, maternal e feminina: imagens da mulher na Revista de Educação Physica. Ijuí: EdUnijuí, 2003b.

GOLDENBERG, M.; RAMOS, M.S. A civilização das formas: o corpo como valor. In: GOLDENBERG, M. (Org.). Nu e vestido: dez antropólogos revelam a cultura do corpo carioca. Rio de Janeiro: Record, 2002. p.19-40.

HABIGZANG, L.F. et al. Abuso sexual infantil e dinâmica familiar: aspectos observados em processos jurídicos. Psicol. Teor. Pesqui., v.21, n.3, p.341-8, 2005.

LOURO, G.L. O cinema como pedagogia. In: LOPES, E.M.; MENDES, L.; VEIGA, C.T.

(Orgs.). 500 anos de educação no Brasil. Belo Horizonte: Autêntica, 2000, p. $423-446$.

MAESTRELLI, S.R.P.; FERRARI, N. O óleo de Lorenzo: o uso do cinema para contextualizar o ensino de genética e discutir a construção do conhecimento científico. Genét. Escola, v.1, n.2, p.35-39, 2006. Disponível em: <http:// www.geneticanaescola.com.br/ano1vol2/02.pdf>. Acesso em: 5 jan. 2011.

MENEGUEL, S.N. O homem elefante: reflexões sobre saúde, doença e anormalidade. Interface - Comunic., Saude, Educ., v.12, n.25, p.427-32, 2008.

NOVAES, J.V.; VILHENA, J. De cinderela a moura torta: sobre a relação mulher, beleza e feiúra. Interações, v.8, n.15, p.9-36, 2003. 
OLIVEIRA, M.L.C.; OLIVEIRA, S.R.N.; IGUMA, L.T. O processo de viver nos filmes: velhice, sexualidade e memória em Copacabana. Texto Contexto Enferm., v.16, n.1, p.157-62, 2007.

PALMA, A.; VILAÇA, M.M. O sedentarismo da epidemiologia. Rev. Bras. Cienc.

Esporte, v.31, n.2, p.105-19, 2010.

PFEIFFER, L.; SALVAGNI, E.P. Visão atual do abuso sexual na infância e adolescência. J. Pediatr., v.81, n.5, p.197-204, 2005.

PRECIOSA: uma história de esperança. Direção Lee Daniels. EUA: PlayArt, 2009. DVD.

RIBEIRO, M.A.; FERRIANI, M.G.C.; REIS, J.N. Violência sexual contra crianças e adolescentes: características relativas à vitimização nas relações familiares. Cad. Saude Publica, v.20, n.2, p.456-64, 2004.

SILVA, T.T. Currículo e identidade social: territórios contestados. In: (Org.) Alienígenas na sala de aula: uma introdução aos estudos culturais em educação. Petrópolis: Vozes, 2001. p.190-207.

GODOI, M.R.; NEVES, L. Cuerpo, la violencia sexual, la vulnerabilidad y la educación libertadora en película "Precious: una historia de la esperanza". Interface - Comunic., Saude, Educ., v.16, n.41, p.409-21, abr./jun. 2012.

El objetivo fue analizar las representaciones del cuerpo (raza, obesidad y belleza), la violencia sexual y los aspectos de vulnerabilidad, educación y empoderamiento experimentado por el protagonista de la película "Precious: Una historia de esperanza". El análisis identifico las representaciones del cuerpo gordo y negro, el rechazo y prejuicio; el deseo de ser bella y famosa; la valoración de su proprio cuerpo y la belleza. La violencia sexual tiene una imagen difusa, como la madre de la protagonista explora la violencia física y psicológica ademas, de encubrir el abuso sexual cometido por su marido y culpabilizar a su hija por lo sucedido. La vulnerabilidad ha sido comprobada en las dimensiones individuales, sociales e institucionales, conrespecto a la violencia sexual. La educación ha jugado un papel importante en el proceso de emancipación de la situación de opreción y de la vulnerabilidad del personaje principal.

Palabras clave: Cuerpo. Imagen corporal. Violencia sexual. Vulnerabilidad. Educación libertadora. 
